\title{
Dopamine infusion for the treatment of myocardial dysfunction associated with a persistent transitional circulation
}

\author{
GARRICK I FIDDLER, RANJIT CHATRATH, GORDON J WILLIAMS, \\ DUNCAN R WALKER, AND OLIVE SCOTT
}

Department of Paediatric Cardiology, Department of Anaesthesia, and Department of Cardiothoracic Surgery, Killingbeck Hospital, Leeds

SUMMARY Four infants with myocardial dysfunction associated with a persistent transitional circulation were given dopamine infusions in addition to standard treatment. The condition of each improved strikingly with rapid diminution in heart size as judged by chest $x$-ray. Dopamine has a place in the management of the sick infant with a persistent transitional circulation.

Dopamine, a catecholamine and an immediate precursor in the synthesis of noradrenaline, increases myocardial contractility and cardiac output by a direct action. Unlike isoprenaline it produces very little increase in heart rate in low to moderate dosage. It also increases renal blood flow and dilates the mesenteric vessels. ${ }^{1-4}$ It has been widely used both in adults and children for the treatment of various forms of shock. ${ }^{4-5}$ As our experience with this drug has been favourable in children and infants requiring inotropic support after surgery for congenital heart disease, we used it in 4 infants with myocardial dysfunction associated with a persistent transitional circulation, and they form the basis of this report.

\section{Case reports}

Case 1. This girl was the fourth child of a mother who had had two normal children and one stillborn child. The pregnancy and delivery were uneventful with normal Apgar scores; birthweight was $3.3 \mathrm{~kg}$. Cyanosis was present shortly after birth and at one hour the arterial blood-gases in room air were $\mathrm{pH}$ $7 \cdot 24, \mathrm{Po}_{2} 4 \cdot 2 \mathrm{kPa}(31 \cdot 6 \mathrm{mmHg}), \mathrm{PcO}_{2} 7 \cdot 8 \mathrm{kPa}(58 \cdot 6$ $\mathrm{mmHg}$ ), base excess $-4 \mathrm{mmol} / \mathrm{l}$. Blood glucose was

\footnotetext{
Killingbeck Hospital, Leeds

Department of Paediatric Cardiology

GARRICK I FIDDLER, senior registrar

GORDON J WILLIAMS, consultant

OLIVE SCOTT, consultant

Department of Anaesthesia

RANJIT CHATRATH, consultant

Department of Cardiothoracic Surgery

DUNCAN R WALKER, consultant
}

$0.5 \mathrm{mmol} / 1(9.0 \mathrm{mg} / 100 \mathrm{ml})$. She was nursed in $40 \%$ oxygen and an IV infusion of $10 \%$ dextrose was started. Because of persisting cyanosis she was transferred to our unit at 5 hours. Examination showed no respiratory distress but moderate cyanosis, not improved by increasing $\mathrm{O}_{2}$ concentrations. The pulses were normal and there was increased activity of the right ventricle on praecordial palpation. The second sound was loud and single and a short grade $2 / 6$ systolic murmur was audible at the lower left sternal edge. There was no hepatomegaly. ECG showed pronounced right atrial enlargement with T-wave changes, suggesting subendocardial ischaemia in all the chest leads. Chest $x$-ray showed prominent right atrium with diminished pulmonary vascularity. The clinical diagnosis was pulmonary atresia with intact ventricular septum but cardiac catheterisation and angiography showed pulmonary hypertension, right-to-left shunting at atrial and ductal levels, mild tricuspid incompetence, and a small persistent ductus arteriosus. The diagnosis of persistent transitional circulation with myocardial dysfunction was made and an IV infusion of dopamine, $2 \mu \mathrm{g} / \mathrm{kg}$ per min, was started and continued for 48 hours, the child being nursed in $40 \%$ $\mathrm{O}_{2}$. After this only slight cyanosis was present and chest $x$-ray showed a pronounced diminution in right atrial size. The baby was then digitalised and a further 48 hours later was acyanotic with a normal ECG. She was discharged home at age 6 days on no therapy and remains well: when last seen at 18 months the murmur had disappeared.

Case 2. This girl was a second child born at term after a normal pregnancy and delivery. Apgar scores 
were normal and birthweight $4 \mathrm{~kg}$. Initial examination showed a normal infant but at one hour she was deeply cyanosed. There was no respiratory distress and peripheral pulses were normal. A short grade $2 / 6$ systolic murmur was audible at the lower left sternal edge. There was no hepatomegaly. Capillary blood-gases in air were $\mathrm{pH} \mathrm{6.78,} \mathrm{Po}_{2}$ $3.9 \mathrm{kPa}(29.3 \mathrm{mmHg}), \mathrm{PCO}_{2} 16.5 \mathrm{kPa}(124 \mathrm{mmHg})$, base excess $-26 \mathrm{mmol} / \mathrm{l}$. Dextrostix was normal. ECG showed right atrial enlargement and severe ischaemic changes in the left chest leads (Fig. 1a), and chest $x$-ray showed gross cardiomegaly with pulmonary venous congestion (Fig. 2a). The baby was thought to have a persistent transitional circulation, mild tricuspid incompetence, and myocardial ischaemia. She was nursed in $60 \% \mathrm{O}_{2}$ and given sodium bicarbonate. At age 8 hours an infusion of dopamine $2.5 \mu \mathrm{g} / \mathrm{kg}$ per min was begun together with digitalisation and frusemide. During the next 12 hours the baby improved strikingly, requiring less oxygen and after 20 hours the dopamine was stopped. By 3 days she was clinically normal with no murmur and both the ECG (Fig. 1b) and chest $x$-ray (Fig. 2b) had returned to near normal. Digoxin and frusemide were stopped on day 5 and she was discharged home at 9 days with no abnormalities. When last seen at 9 months she appeared to be progressing normally.

Case 3. This boy, the first child, was delivered by caesarean section at 38 weeks' gestation for fetal distress. Low oestriol values had been found in the pregnancy. Apgar scores were 2 at one minute and 7 at six minutes, birthweight $2.9 \mathrm{~kg}$. Cyanosis was present from birth and there was pronounced pitting oedema over the face, chest wall, and abdomen. Because of persisting cyanosis even in $\mathrm{O}_{2}$ he was transferred to our unit at one day. Examination showed moderate cyanosis in air with mild respiratory distress. Facial and truncal oedema was still present. Peripheral pulses were normal and the second heart sound was loud and single. There were no murmurs. The liver was enlarged $3 \mathrm{~cm}$ at the right costal margin. Arterial blood-gases in air were $\mathrm{pH} 7 \cdot 15, \mathrm{Po}_{2} 7 \cdot 54 \mathrm{kPa}(56 \cdot 7 \mathrm{mmHg}), \mathrm{PcO}_{2} 9 \cdot 55$ (a)
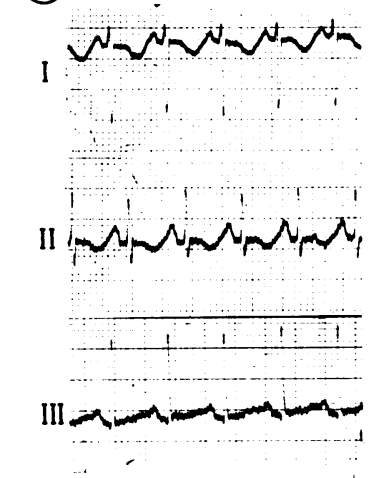

aVR
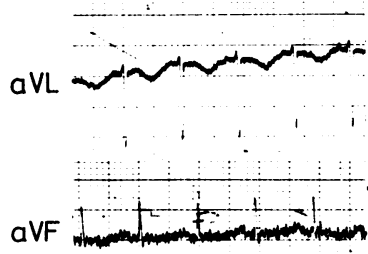

(b)
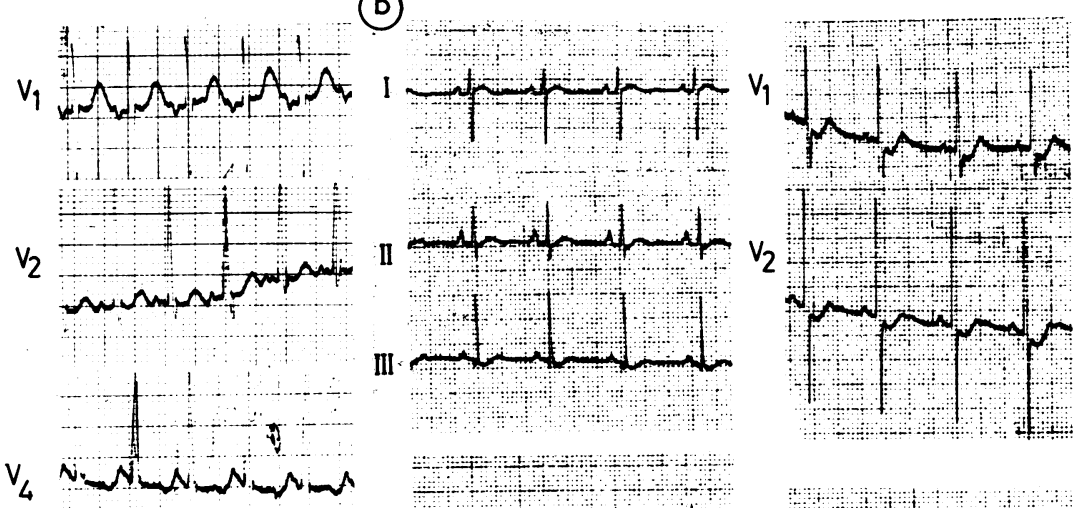

aVR
$\mathrm{faVL}$

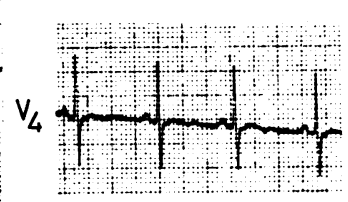

$v_{6}$
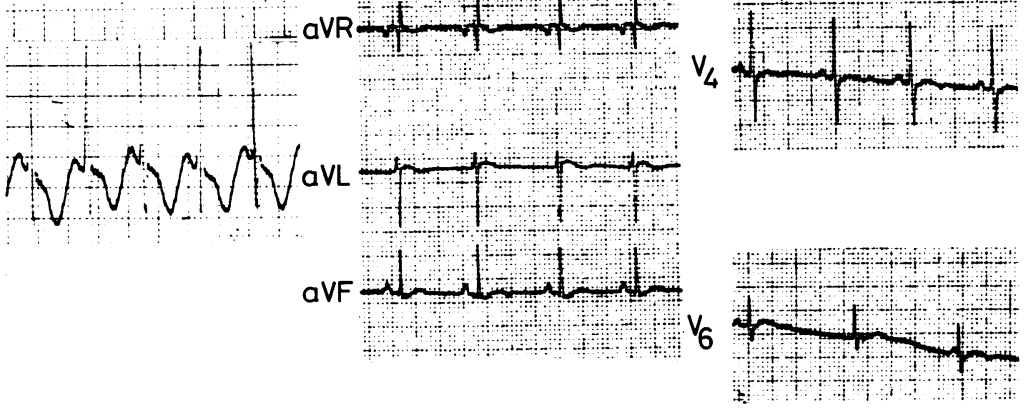

Fig. 1 (Case 2). Electrocardiograms showing (a) peaked P-waves of right atrial enlargement in lead II, with ischaemic $S$-T segment changes in left chest leads $(b)$ resolution of right atrial enlargement and myocardial ischaemia. 


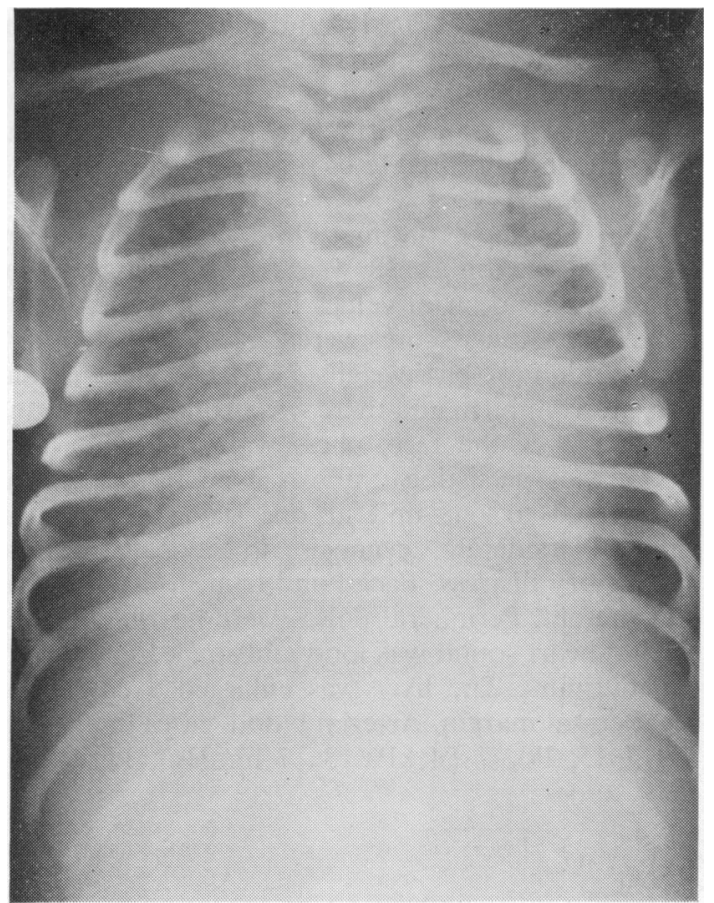

(a)

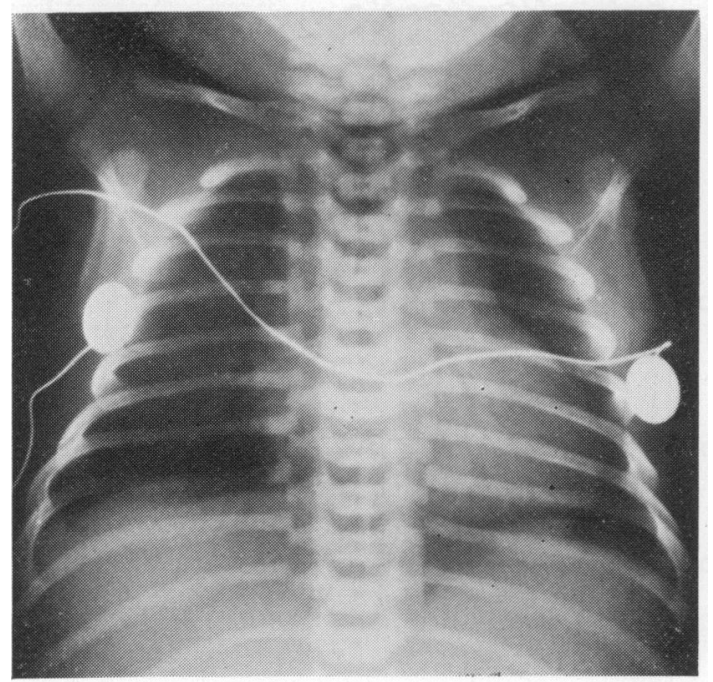

(b)

Fig. 2 (Case 2). Chest $x$-rays showing

(a) cardiomegaly and pulmonary venous congestion

(b) diminution in heart size and normal lung fields.
$\mathrm{kPa}(71 \cdot 8 \mathrm{mmHg})$, base excess $-6 \mathrm{mmol} / \mathrm{l}$. Dextrostix was normal. ECG showed right ventricular dominance with poor left ventricular forces, and chest $x$-ray showed massive cardiomegaly. An echocardiogram was within normal limits. Because of the perinatal asphyxia, a persistent transitional circulation with myocardial dysfunction causing gross cardiac failure was diagnosed. The baby was nursed in $40 \% \mathrm{O}_{2}$ and given digoxin and frusemide. After this there was slight clinical improvement but the urine output remained poor and a dopamine infusion $5 \mu \mathrm{g} / \mathrm{kg}$ per min was begun. After 48 hours there was a striking clinical improvement with oedema almost cleared and chest $x$-ray returning to normal. Dopamine was stopped and the baby was eventually discharged home at 11 days with no abnormalities and on no therapy.

Case 4. This boy, the second child, was born after a normal pregnancy and delivery. Apgar scores were 2 at one minute and 8 at five minutes, birthweight $3 \mathrm{~kg}$. Some meconium was aspirated from the pharynx. At 2 hours he was deeply cyanosed and the blood glucose level was $0.6 \mathrm{mmol} / 1(10.8 \mathrm{mg} / 100 \mathrm{ml})$. Arterial blood-gases in $65 \% \mathrm{O}_{2}$ were $\mathrm{pH} 7 \cdot 15$, $\mathrm{Po}_{2} 2.5 \mathrm{kPa}(18.8 \mathrm{mmHg}), \mathrm{PCO}_{2} 6.9 \mathrm{kPa}(51.9$ $\mathrm{mmHg}$ ), base excess $-8.4 \mathrm{mmol} / \mathrm{l}$. Bicarbonate, digoxin, and frusemide were given and a dextrose infusion started. Because of persistent cyanosis the patient was transferred to our unit at 8 hours. Examination showed an ill, cyanosed baby with pink frothy fluid oozing from the pharynx. Coarse crepitations were present over both lungs. Pulses were normal and the second heart sound was loud and single, with a grade $2 / 6$ long systolic murmur at the lower left sternal edge. The liver was enlarged $3 \mathrm{~cm}$ at the right costal margin. ECG showed right atrial enlargement, and chest $x$-ray cardiomegaly with pulmonary oedema. Because of the perinatal asphyxia and hypoglycaemia the left ventricular failure was thought to be associated with a persistent transitional circulation. The baby was intubated and ventilated and an infusion of dopamine $5 \mu \mathrm{g} / \mathrm{kg}$ per min was given for 48 hours. Digoxin was also given and continued for a further 3 days. The baby's condition rapidly improved and he was extubated after 60 hours of ventilation. Heart size and lung fields had by then returned to normal on chest $x$-ray. Echocardiography was performed on day 6 and was normal. He was discharged home on day 12 , well and on no therapy.

\section{Discussion}

Pulmonary hypertension with a fetal direction of ductus arteriosus flow, otherwise known as a 
persistent transitional circulation, has been increasingly recognised in the last decade as being associated with various forms of cardiorespiratory distress in the newborn infant. ${ }^{6-9}$ The exact aetiology is unknown in many cases but polycythaemia, hypoglycaemia, and hypocalcaemia are known to be aggravating factors. A history of fetal distress or hypoxia is also significant. ${ }^{8-9}$ The resulting clinical features depend on the response of the pulmonary vascular bed or the myocardium, or both, to the presumed insult. There is a spectrum of clinical presentation with cyanosis as the main feature, which may or may not respond to oxygen administration. The degree of cyanosis depends on the state of the pulmonary vascular bed, and the presence of intracardiac as well as ductal right-to-left shunting. Myocardial ischaemia ${ }^{7}$ may be present resulting in myocardial dysfunction. This may cause cardiomegaly and venous congestion detectable radiologically, or overt clinical evidence of cardiac failure. Murmurs of tricuspid incompetence are common and may be related to right ventricular dilatation from pulmonary hypertension or subendocardial ischaemia affecting the tricuspid papillary musculature, or a combination of both factors. This problem is usually transient with the murmur eventually disappearing. ${ }^{10-11}$

Two of the patients (Cases 3 and 4) had perinatal asphyxia and two also had hypoglycaemia (Cases 1 and 4). Cases 3 and 4 also had obvious clinical evidence of cardiac failure. Cases 1, 2, and 4 had murmurs of tricuspid incompetence and the murmurs eventually disappeared in all three.

Treatment consisting of oxygen administration, with or without ventilation, and correction of biochemical disturbances produced improvement in many cases. ${ }^{8-912}$ In those patients with severe cyanosis, acidosis, and hypoxaemia, as reported here, a vicious cycle of events occurs with intense pulmonary vasoconstriction and myocardial dysfunction. Additional treatment for this group has been aimed at supporting the myocardium with digoxin and diuretics, and dilating the pulmonary vascular bed with either the $\alpha$-blocker tolazoline, ${ }^{13}$ or the direct vasodilator nitroprusside. ${ }^{14}$ Tolazoline is an effective agent but in one report was shown to have side effects in $30 \%$ of cases when used for the treatment of pulmonary vasoconstriction, ${ }^{13}$ especially haemorrhage and renal abnormalities.

Dopamine has three distinct dose-dependent actions. ${ }^{1-4}$ Low doses (1-2 $\mu \mathrm{g} / \mathrm{kg}$ per min) produce vasodilatation of the mesenteric, renal, coronary, and cerebral blood vessels with a reduction of the total peripheral resistance. No cardiac effect is seen in this dose range. Medium doses (2-10 $\mu \mathrm{g} / \mathrm{kg}$ per min) have a direct effect on the beta adrenergic cardiac receptors causing an increase in cardiac output. Doses greater than $10 \mu \mathrm{g} / \mathrm{kg}$ per min produce vasoconstriction because of $\alpha$-adrenergic stimulation, and arterial blood pressure increases as total peripheral resistance increases.

It has been reported to be a safe drug in doses below $10 \mu \mathrm{g} / \mathrm{kg}$ per min, the only side effects being nausea and vomiting. In doses greater than this extreme caution must be used because severe vasoconstriction can lead to gangrene. ${ }^{15} \mathrm{~A}$ recent study of the use of dopamine in 24 children ranging in age from 2 days to 18 years has shown it to be a safe effective drug in a mean dose of $9 \cdot 3 \mu \mathrm{g} / \mathrm{kg}$ per min. ${ }^{5}$

The use of dopamine in the persistent transitional circulation has not previously been reported. It has been used with some success in combination with chlorpromazine and methylprednisolone as pulmonary vasodilators to manage infants with diaphragmatic hernia and high pulmonary vascular resistance. ${ }^{16}$ It offers immediate inotropic support for the hypoxic failing myocardium, and by dilating peripheral vascular beds reduces some of the after load on the heart. It does not alter the pulmonary vascular resistance if given in low to medium dosage, but we believe it has a place in the management of myocardial dysfunction associated with a persistent transitional circulation, when used with adequate oxygenation and correction of biochemical disturbances. Our experience suggests that it hastens the resolution of the myocardial dysfunction preventing further damage.

We thank Dr J Littlewood, Dr G Lealman, Dr W Arrowsmith, and Dr J Ellis for referring the patients.

\section{References}

1 Editorial: Dopamine in cardiac failure and shock. $\mathrm{Br}$ Med $J$ 1977; ii: 1563-4.

2 Goldberg L I, Msieh Y Y, Resnekov L. Newer catecholamines for the treatment of heart failure and shock. An update on dopamine and a first look at dobutamine. Prog Cardiovasc Dis 1977; 19: 327-40.

3 Editorial: Intravenous dopamine. Lancet 1977; 2: 231-2.

4 Mennie A T, ed. Dopamine hydrochloride. Proceedings of an International Symposium held at the Royal Society of Medicine by Arnar-Stone Laboratories on 30 June 1976. Proc R Soc Med 1977; 70: Supplement 2.

5 Driscoll D J, Gillette P C, McNamara D G. The use of dopamine in children. J Pediatr 1978; 92: 309-14.

6 Roberton N R C, Hallidie-Smith K A, Davis J A. Severe respiratory distress syndrome mimicking cyanotic heart disease in term babies. Lancet 1967; 2: 1108-10.

7 Rowe R D, Hoffman T. Transient myocardial ischemia of the newborn infant: a form of severe cardiorespiratory distress in full-term infants. J Pediatr 1972; 81 : 243-50.

8 Brown R, Pickering D. Persistent transitional circulation. Arch Dis Child 1974; 49: 883-5. 
9 Rowe R D. Abnormal pulmonary vasoconstriction in the newborn. Pediatrics 1977; 59: 318-21.

10 Boucek R J, Jr, Graham T P, Jr, Morgan J P, Atwood G F, Boerth R C. Spontaneous resolution of massive congenital tricuspid insufficiency. Circulation 1976; 54: 795-800.

11 Bucciarelli R L, Nelson R M, Egan F A, II, Eitzman D V, Gessner I M. Transient tricuspid insufficiency of the newborn: a form of myocardial dysfunction in stressed newborns. Pediatrics 1977; 59: 330-7.

12 Riemenschneider T A, Nielsen H C, Ruttenberg M D, Jaffe R B. Disturbances of the transitional circulationspectrum of pulmonary hypertension and myocardial dysfunction. JPediatr 1976; 89: 622-5.

13 Goetzman B W, Sunshine P, Johnson J D, et al. Neonatal hypoxia and pulmonary vasospasm. Response to tolazoline. J Pediatr 1976; 89: 617-21.
14 Abbott T R, Rees G J, Dickinson D, Reynolds G, Lord D. Sodium nitroprusside in idiopathic respiratory distress syndrome. $\mathrm{Br}$ Med J 1978; i : 1113-4.

15 Stetson J B, Reading G P. Avoidance of vascular complications associated with the use of dopamine. Can Anaesth Soc J 1977; 24: 727-33.

16 Dibbins A W. Neonatal diaphragmatic hernia: a physiologic challenge. Am J Surg 1976; 131 : 408-9.

Correspondence to Dr G I Fiddler, Department of Paediatric Cardiology, Killingbeck Hospital, York Road, Leeds LS14 6 UQ.

Received 15 March 1979

The following articles will appear in future issues of this journal:

Serum 25-hydroxy-vitamin D levels in malnourished children with rickets. $N$ Raghuramulu and V Reddy

Ileal meconium plugs. $V C$ Talwalker and $D$ H Kittur

Follow-up of children with diabetic mothers. M Cummins and $M$ Norrish

Pharmacological closure of ductus arteriosus in preterm infants using indomethacin. $H I$ Obeyesekere, $S$ Pankhurst, and $V Y H Y u$

Metoclopramide poisoning in children. $L C K$ Low and $K M$ Goel

$Q$ fever endocarditis in a 6-year-old child. $R W A$ Jones and $D W$ Pitcher 